\title{
A New Approach to Farm Biodiversity Assessment
}

\author{
Stanisław Świtek ${ }^{1, * \mathbb{D}}$, Zuzanna Sawinska ${ }^{1}$ and Romana Głowicka-Wołoszyn ${ }^{2}$ \\ 1 Department of Agronomy, Poznań University of Life Sciences, 11 Dojazd St, 60-632 Poznań, Poland; \\ zuzanna.sawinska@up.poznan.pl \\ 2 Department of Finance and Accounting, Poznań University of Life Sciences, 28 Wojska Polskiego St, \\ 60-637 Poznań, Poland; roma@up.poznan.pl \\ * Correspondence: stanislaw.switek@up.poznan.pl; Tel.: +48-61-846-7405
}

Received: 8 August 2019; Accepted: 4 September 2019; Published: 14 September 2019

\begin{abstract}
A reduction in biodiversity due to farming operations has been broadly reported. As a solution, policy makers in the European Union have introduced several programs in recent years to enhance biodiversity on farms but these have met with only limited success. One of the main reasons for this lack of success is that the experience, knowledge and attitudes of farmers are not taken into account when biodiversity conservation programs are formulated. Farmers' opinions must be taken into consideration in the creation of future programs, which should also include an assessment by the farmers of the value of the nature of their farms. In this study, farmers were asked to express their opinion on the attractiveness of their farm in relation to pollinators, game, birds, amphibians, reptiles, rodents and non-crop (wild) plants. Data were then analysed using a novel method in which each farm was assigned to one of four categories. High nature-value farms contained more natural features in the landscape, such as individual trees or ponds. Socio-economic factors, such as gender, also influenced the farm assessments; female farmers were more critical compared to their male counterparts. The establishment of field margins or watercourse by the farmers significantly increased the possibility that the farm would be classified as attractive.
\end{abstract}

Keywords: biodiversity; CAP; conservation; EFA; farmland; TOPSIS

\section{Introduction}

Biodiversity loss has become a major global problem [1,2]. Farming has a strong impact on this process and affects the environment more than any other land use type [3]. Increased agricultural productivity has caused ecologically negative consequences [4] as the landscape has been homogenised, semi-natural habitats have been lost or fragmented [5], and the numbers of many species of plants and animals have decreased [6-8]. Politicians have attempted to halt this problem by implementing a range of programs. For example, a reformed Common Agricultural Policy (CAP) was introduced in 2014 under the auspices of the European Union and contained a so-called greening program that obligates farmers to diversify in crop production, maintain permanent grassland and allocate $5 \%$ of agricultural land to ecological focus areas (EFA) [9]. Profitable food production, sustainable resource management, balanced territorial development and the support of public goods, such as landscape or ecological functionality, are long-term goals of the program [10-12]. Under the various conservation programs, the farm must become an attractive place for nature, in turn maintaining or even increasing the level of biodiversity. Unfortunately, a large number of studies have indicated that the goals of greening, as with other conservative programs, have not been achieved and have had a minimal impact on farming practices [13]. Instead, research has shown that efforts should be focused on a farmland biological conservation program, which considers biodiversity and the factors that determine the decisions of farmers [14]. In general, farmers do not like changes to their production methods [15]. 
However, their opinions and how their actions are influenced by their perception of the environment are often overlooked [16]. Therefore, we assessed how farmers perceive the natural value of their farms, which is important in the context of the effectiveness of introduced nature conservation programs. Specifically, the opinions of farmers in relation to the following groups were examined:

(1) Pollinators are an important component of the ecosystem services provided by the environment [17] and their abundance is correlated with plant species [18] and landscape heterogeneity [19]. (2) Game species depend on the availability of food, the prevalence of shelter habitats, and state policy towards wild animals. Populations are positively affected by the provision of suitable conditions [20]. (3) Species richness of bird populations is highest in mixed agricultural areas that have a high proportion of habitats edged by trees. The composition and species richness of bird populations may be indicative of the condition of the wider landscape and the occurrence of natural features [21], as well as the intensity of land use [22]. (4) Populations of amphibians and reptiles are determined by the landscape; a highly heterogeneous environment favours amphibian diversity [23,24]. (5) Rodents can provide benefits for farmers, for example, by eating weed seeds, but are also problematic as they can destroy crop plants [25]. A homogenous landscape can reduce rodent populations but will also impact on the biodiversity of the agricultural land [26]. (6) Species richness of non-crop (wild) plants is influenced by farming practices. The presence of non-crop plants has a high impact on the entire ecosystem [27].

The main objective of our research was to assess the nature-value of farms from the viewpoint of their owners, and to identify the determining factors: demographic, economic and environmental. Thus, the following research questions were asked:

1. Is the nature-value of their farm important for farmers and does it play a role in decision making?

2. Does the economic value of the farm influence the perception of its nature-value?

3. Does the occurrence of natural features, such as trees, ditches or ponds, improve the assessment of the nature-value of farms? An additional objective of the research was an attempt to link the subjective assessment of the farm's nature-value (provided by the farmers) with farm management actions that have an impact on that nature-value.

\section{Materials and Methods}

The research was based on a survey conducted with farmers across Poland. The survey was conducted in 2017 using the questionnaire interview method under the supervision of the authors. A total of 275 interviews was carried out, of which 273 complete interviews were used for the analysis.

In the survey, six questions concerned the subjective assessment of the natural attractiveness of a farm. This attractiveness was assessed for pollinators, wild game, birds, rodents, amphibians and reptiles, and weeds and herbs. In this way, six simple features (six diagnostic variables) describing the attractiveness of the farm were obtained.

To construct a synthetic indicator of the subjective assessment of the natural attractiveness of farms (SISAF), taking into account all one-dimensional assessments at the same time, the multidimensional linear ordering method TOPSIS (Technique for Order of Preference by Similarity to Ideal Solution) was used [28-30]. The highest and lowest scores for each diagnostic variable were adopted as reference values (positive and negative ideal solutions). The construction of the synthetic indicator by this method requires the calculation of the distance of each object (farm) from the adopted best and worst condition. Due to the fact that the variables were measured on an ordinal rather than an interval scale, the most universal generalized distance measure (GDM) was used to determine the distance [31,32].

The determined values of the synthetic measure allowed classification of the researched farms in terms of their natural attractiveness (simultaneously in all six considered dimensions) and a typology of separate classes based on a one-dimensional analysis of the value of diagnostic variables in each class. In addition, the classification of farms into one of four classes allowed the use of a more advanced method: the generalized logit model of ordered categories [33] to identify internal socio-economic conditions that increase the assessment of the natural attractiveness of farms. 
The general scheme of the test, consisting of four stages, is presented in Figure 1.

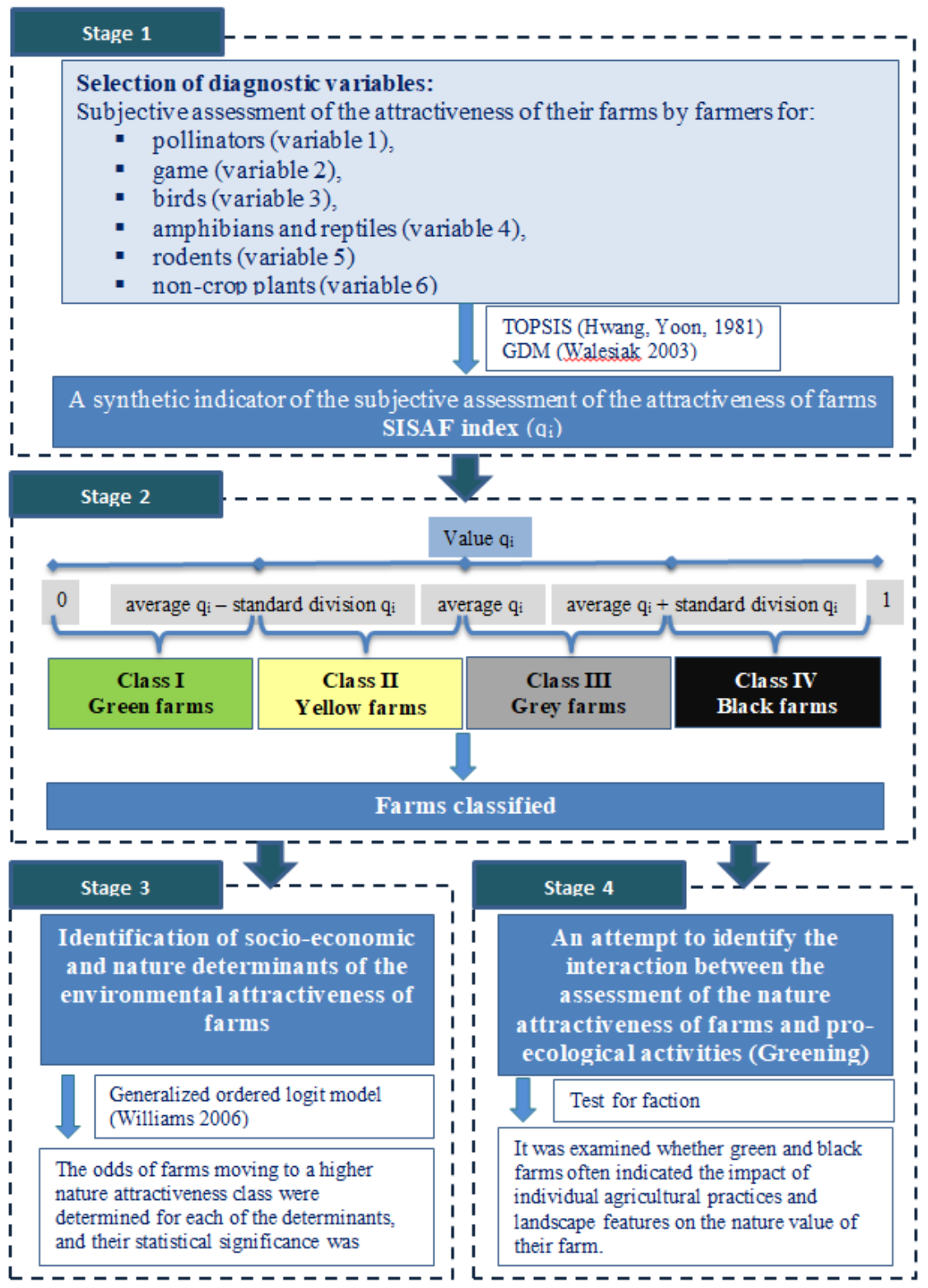

Figure 1. General scheme of the study's farm biodiversity based on farmers' assessments with the Technique for Order of Preference by Similarity to Ideal Solution (TOPSIS) and generalized distance measure (GDM) methods used.

\subsection{Stage 1}

The construction of a synthetic indicator of the subjective assessment of the natural attractiveness of farms was carried out in five steps:

Step 1. A set of diagnostic variables was determined (dimensions of a farm's natural attractiveness $X_{k}$, where $\left.k=1-6\right)$ :

$X_{1}$-subjective assessment of farm attractiveness for pollinators;

$X_{2}$-a subjective assessment of the attractiveness of the farm for game;

$X_{3}$-subjective assessment of the attractiveness of the farm for birds;

$X_{4}$-subjective assessment of farm attractiveness for amphibians and reptiles;

$\mathrm{X}_{5}$ - subjective assessment of the attractiveness of the farm for rodents; 
$X_{6}$ - subjective assessment of the attractiveness of the farm for non-crop plants.

Observations of each diagnostic variable were expressed on the ordinal scale:

1 -very unattractive;

2-rather unattractive;

3-medium;

4-rather attractive;

5-very attractive.

Each of the diagnostic variables was a measure of the subjective natural attractiveness of the farm. Each farm was characterized by a vector of diagnostic variables:

$$
X_{i k}=\left[X_{i 1}, X_{i 2}, X_{i 3}, X_{i 4}, X_{i 5}, X_{i 6}\right]
$$

where $i=1-n$ ( $n=273$ farms); $k=1-6$ (number of diagnostic variables).

Step 2. The values of the diagnostic variables were standardized according to the following formula:

$$
z_{i k}=\frac{x_{i k}-\min _{i}\left\{x_{i k}\right\}}{\max _{i}\left\{x_{i k}\right\}-\min _{i}\left\{x_{i k}\right\}}
$$

where: $X_{i k}$ is the value of the $k^{\text {th }}$ variable for the $i^{\text {th }}$ farm; $k=1, \ldots, 6 ; I=1, \ldots, 273$.

Step 3. Reference (model) values of positive $\left(A^{+}\right)$and negative $\left(A^{-}\right)$ideal solutions (maximum and minimum values) were determined for each diagnostic variable separately:

$$
\begin{aligned}
A^{+} & =\left(\max _{i}\left(X_{i 1}\right), \max _{i}\left(X_{i 2}\right), \ldots, \max _{i}\left(X_{i k}\right)\right) \\
A^{-} & =\left(\min _{i}\left(X_{I 1}\right), \min _{i}\left(X_{i 2}\right), \ldots, \min _{i}\left(X_{i k}\right)\right)
\end{aligned}
$$

Step 4 . The construction of the synthetic indicator using the TOPSIS method requires calculating the distance of each object (farm) from its worst and best condition. Due to the fact that the variables were measured on an ordinal rather than a metric scale, the most universal GDM was used to determine the distance [31,32]:

The distance of objects (farms) was calculated for each diagnostic variable from positive $\left(A^{+}\right)$and negative $\left(A^{-}\right)$ideal solutions using GDM:

$$
d_{i j}^{(*)}=\frac{1}{2}-\frac{\sum_{k=1}^{K} a_{i j k} b_{i j k}+\sum_{k=1}^{K} \sum_{l=1}^{N+2} a_{i l k} b_{j l k}}{2\left[\left(\sum_{k=1}^{K} a_{i j k}^{2}+\sum_{k=1}^{K} \sum_{l=1, l \neq i, j}^{N+2} a_{i l k}^{2}\right)\left(\sum_{k=1}^{K} b_{i j k}^{2}+\sum_{k=1}^{K} \sum_{l=1, l \neq i, j}^{N+2} b_{i l k}^{2}\right)\right]^{\frac{1}{2}}}
$$

where: $i=1-n$ and $j=n+1, n+2,\left(^{*}\right)$ are alternative positive and negative ideal solutions.

Substitution is used for features measured on the ordinal scale:

$$
a_{i u k}\left(b_{j t k}\right)=\left\{\begin{array}{cc}
1 & x_{i k}>x_{u k}\left(x_{j k}>x_{t k}\right) \\
0 & x_{i k}=x_{u k}\left(x_{j k}=x_{t k}\right) \\
-1 & x_{i k}<x_{u k}\left(x_{j k}<x_{t k}\right)
\end{array}\right.
$$

where: $X_{i k}\left(X_{j k}, X_{l k}, X_{u k}, X_{t k}\right)$-is observation $i(j, l, u, t)$ for the $k^{\text {th }}$ diagnostic variable. 
Step 5. Values for the SISAF index were calculated:

$$
q_{i}=\frac{d_{i}^{-}}{d_{i}^{+}+d_{i}^{-}}
$$

where: $0 \leq q_{\mathrm{i}} \leq 1 ; i=1-273$.

\subsection{Stage 2}

On the basis of the obtained SISAF index values, the farms were classified and the typology of the classes was made. Four classes were determined using a statistical criterion based on the average and standard division $\left(s_{q}\right)$ of the SISAF index. A color was assigned to each class to facilitate the interpretation of results:

Class I: Green farms-high nature-value $\left(q_{i} \geq \bar{q}+s_{q}\right)$;

Class II: Yellow farms-medium to high nature-value $\left(\bar{q} \leq q_{i}<\bar{q}+s_{q}\right)$;

Class III: Grey farms-medium to low nature-value $\left(\bar{q}-s_{q} \leq q_{i}<\bar{q}\right)$;

Class IV: Black farms-low nature-value $\left(q_{i}<\bar{q}-s_{q}\right)$.

The calculations were performed with the clusterSim package of the R program

\subsection{Stage 3}

The next step was to identify factors that influence how the nature-value of the farms is assessed. These were divided into socio-economic (gender and age of the farmer, and size of the farm) and natural (occurrence of natural features, such as trees, ponds and hedgerows) factors. For this purpose, a logit model for ordered categories was used [33]. The Brant model [34], to verify the assumption of proportional opportunities was used.

So-called cumulative logits were modeling logarithms of the quotients of the probability of the $i^{\text {th }}$ farm belonging to the subjective category of its attractiveness, not higher than $j^{\text {th }} \operatorname{Pr}\left(y_{i} \leq y_{j}\right)$ and the opposite probability $\operatorname{Pr}\left(y_{i}>y_{j}\right)$.

In the case of J categories, J-1 equations are obtained [33]:

$$
\operatorname{Pr}\left(y_{i}>j\right)=\frac{\exp \left(\alpha_{j}+x_{i 1} \beta_{1 j}+x_{i 2} \beta_{2 j}+\ldots+x_{i K} \beta_{K j}\right)}{1+\exp \left(\alpha_{j}+x_{i 1} \beta_{1 j}+x_{i 2} \beta_{2 j}+\ldots+x_{i K} \beta_{K j}\right)}
$$

Alternatively, the model could be written in terms of the cumulative distribution function:

$$
\begin{gathered}
\operatorname{Pr}\left(y_{i} \leq j\right)=1-\operatorname{Pr}\left(y_{i}>j\right) \\
\operatorname{logit}\left[\operatorname{Pr}\left(y_{i} \leq j\right)\right]=\ln \frac{\operatorname{Pr}\left(y_{i} \leq j\right)}{\operatorname{Pr}\left(y_{i}>j\right)}=\alpha_{j}+x_{i 1} \beta_{1 j}+x_{i 2} \beta_{2 j}+\ldots+x_{i K} \beta_{K j}
\end{gathered}
$$

where $i=1,2, \ldots n$ and $j=1,2, \ldots, \mathrm{J}-1$.

The dependent variable and independent variables used in the logit model are listed in Table 1.

Each of the categories are the reference points for the other categories, and their odds ratios assume a value of 1 . For the other categories, the odds ratios have a simple interpretation: values greater than 1 indicate greater chances of moving to higher classes of subjective assessment of natural attractiveness than in the reference category farms, and vice versa.

The calculations were performed with the clusterSim package of the $\mathrm{R}$ program and in STATA using the gologit2 package published by Williams [33]. 
Table 1. Characteristics of dependent and independent variables used in the generalized model of ordered logit regression.

\begin{tabular}{|c|c|c|c|}
\hline \multicolumn{3}{|c|}{ Type of Variable } & \multirow{2}{*}{$\begin{array}{c}\text { Definition (Units/Categories) } \\
\text { 1-high } \\
\text { 2-medium-high } \\
\text { 3-medium-low } \\
\text { 4-low }\end{array}$} \\
\hline Dependent variable: & $\begin{array}{l}\text { Subjective synthetic } \\
\text { assessment of the farm's } \\
\text { natural attractiveness }\end{array}$ & & \\
\hline \multirow[b]{2}{*}{ Independent variables: } & $\begin{array}{l}\text { Socio-economic } \\
\text { conditions for farms }\end{array}$ & $\begin{array}{c}\text { Sex } \\
\text { Farm area } \\
\text { Age of farmers } \\
\text { Farm development }\end{array}$ & $\begin{array}{c}\text { (female/male) } \\
\text { (ha) } \\
\text { (years) } \\
\text { Has farm area increased in the } \\
\text { last } 10 \text { years (yes/no) }\end{array}$ \\
\hline & $\begin{array}{l}\text { Natural features } \\
\text { occurring on the farm }\end{array}$ & $\begin{array}{c}\text { Individual trees } \\
\text { Field margins } \\
\text { Ponds } \\
\text { Ditches up to } 2 \mathrm{~m} \text { wide } \\
\text { Watercourse } \\
\text { Line of trees } \\
\text { Groups of trees } \\
\text { Hedges and Shelter belts }\end{array}$ & $\begin{array}{l}\text { (yes/no) } \\
\text { (yes/no) } \\
\text { (yes/no) } \\
\text { (yes/no) } \\
\text { (yes/no) } \\
\text { (yes/no) } \\
\text { (yes/no) } \\
\text { (yes/no) }\end{array}$ \\
\hline
\end{tabular}

\subsection{Stage 4}

The final stage combined an assessment of the nature-value of farms with pro-ecological activities undertaken and declared by the surveyed farmers and activities related to the greening program.

\section{Results}

\subsection{Farms' Characteristics}

These were based on the answers given by farmers in regard to the attractiveness of their farm to pollinators, game, birds, amphibians and reptiles, rodents and non-crop plants. The farms were assigned to one of four groups. In the subjective assessment, the largest group (over $36 \%$ ) of farmers considered that their farm had a medium low nature-value (Class III/Grey farms) (Table 1). Approximately $25 \%$ considered their farms as medium high (Class II/Yellow farms), $22 \%$ of farmers considered their farms to have a high nature-value (Class I/Green farms), and 16\% considered their farms as low (Class IV/Black farms) (Table 2).

Table 2. Characteristics of the farms assessed in this study.

\begin{tabular}{cccccc}
\hline \multirow{2}{*}{ Specification } & \multicolumn{2}{c}{ Assessment of the Farm Nature-Value-Typological Classes } & \multirow{2}{*}{ Total } \\
\cline { 2 - 5 } & High & Medium High & Medium Low & Low & \\
\hline Class & I & II & III & IV & \\
Names of class & Green farms & Yellow farms & Grey farms & Black farms & \\
Synthetic index & $0.77-1.00$ & $0.52-0.77$ & $0.28-0.52$ & $0.00-0.28$ & \\
Number of farms & 61 & 69 & 99 & 44 & 273 \\
$\%$ of farms & $22.3 \%$ & $25.3 \%$ & $36.3 \%$ & $16.1 \%$ & $100.0 \%$ \\
\hline
\end{tabular}

\subsection{Typological Classes of Farm Attractiveness}

Green farms are farms with a high nature-value assessment (Class I). Of these, $60 \%$ were rated as very attractive for game, about $40 \%$ for birds, $30 \%$ for pollinators, rodents, and non-crop (wild) plants, and about $20 \%$ for amphibians and reptiles. Moreover, $97 \%$ of green farms were considered attractive or very attractive for pollinators. In this group, there were no unattractive farms for pollinators, game, or birds, but a small proportion of farms $(2 \%-5 \%)$ were considered unattractive for amphibians and reptiles, rodents, and non-crop plants. 
Black farms are farms classified as low nature-value. A total of $95 \%$ of these farmers believed that their farms were unattractive or very unattractive for amphibians and reptiles, $80 \%$ for rodents, over $70 \%$ for non-crop plants and over 50\% for birds and game. Around $45 \%$ of farms in this group were defined as neutral for pollinators, and approximately $30 \%$ of the owners described them as attractive or very attractive.

The largest number of farms were assessed as Grey farms (36\%) and Yellow farms (25\%). In Grey farms, a neutral assessment of the attractiveness for animal and plant species predominated, with the exception of wild game, where an attractive or very attractive rating predominated. In contrast, slightly higher ratings prevailed in Yellow farms, because the farms were usually rated as attractive, with the exception of amphibians, reptiles and non-crop plants where a neutral rating dominated (Table 3).

Table 3. Typology of subjective classes related to nature-value of the farm.

\begin{tabular}{|c|c|c|c|c|c|}
\hline \multirow{2}{*}{ Farm Attractiveness for } & \multicolumn{5}{|c|}{ Assessment of the Farm's Attractiveness-Typological Classes } \\
\hline & Green Farms & Yellow Farms & Grey Farms & Black Farms & Total \\
\hline \multicolumn{6}{|c|}{ Percentage of farms in each class $(\%)$} \\
\hline \multicolumn{6}{|c|}{ Pollinators: } \\
\hline Very unattractive & 0.0 & 1.4 & 3.0 & 9.1 & 2.9 \\
\hline Rather unattractive & 0.0 & 2.9 & 4.0 & 15.9 & 4.8 \\
\hline Medium & 3.3 & 11.6 & 42.4 & 45.5 & 26.4 \\
\hline Rather attractive & 62.3 & 60.9 & 37.4 & 25.0 & 46.9 \\
\hline Very attractive & 34.4 & 23.2 & 13.1 & 4.5 & 19.0 \\
\hline \multicolumn{6}{|c|}{ Game: } \\
\hline Very unattractive & 0.0 & 0.0 & 2.0 & 29.5 & 5.5 \\
\hline Rather unattractive & 0.0 & 5.8 & 5.1 & 25.0 & 7.3 \\
\hline Medium & 0.0 & 5.8 & 39.4 & 31.8 & 20.9 \\
\hline Rather attractive & 39.3 & 50.7 & 46.5 & 13.6 & 40.7 \\
\hline Very attractive & 60.7 & 37.7 & 7.1 & 0.0 & 25.6 \\
\hline \multicolumn{6}{|c|}{ Birds: } \\
\hline Very unattractive & 0.0 & 1.4 & 0.0 & 13.6 & 2.6 \\
\hline Rather unattractive & 0.0 & 0.0 & 10.1 & 45.5 & 11.0 \\
\hline Medium & 0.0 & 15.9 & 59.6 & 36.4 & 31.5 \\
\hline Rather attractive & 60.7 & 66.7 & 29.3 & 4.5 & 41.8 \\
\hline Very attractive & 39.3 & 15.9 & 1.0 & 0.0 & 13.2 \\
\hline \multicolumn{6}{|c|}{ Amphibian and reptiles: } \\
\hline Very unattractive & 0.0 & 5.8 & 11.1 & 36.4 & 11.4 \\
\hline Rather unattractive & 4.9 & 13.0 & 35.4 & 59.1 & 26.7 \\
\hline Medium & 19.7 & 44.9 & 46.5 & 2.3 & 33.0 \\
\hline Rather attractive & 54.1 & 27.5 & 6.1 & 2.3 & 21.6 \\
\hline Very attractive & 21.3 & 8.7 & 1.0 & 0.0 & 7.3 \\
\hline \multicolumn{6}{|c|}{ Rodents: } \\
\hline Very unattractive & 0.0 & 1.4 & 4.0 & 31.8 & 7.0 \\
\hline Rather unattractive & 3.3 & 5.8 & 31.3 & 47.7 & 21.2 \\
\hline Medium & 8.2 & 34.8 & 51.5 & 20.5 & 32.6 \\
\hline Rather attractive & 57.4 & 44.9 & 11.1 & 0.0 & 28.2 \\
\hline Very attractive & 31.1 & 13.0 & 2.0 & 0.0 & 11.0 \\
\hline \multicolumn{6}{|c|}{ Non-crop plants: } \\
\hline Very unattractive & 1.6 & 4.3 & 9.1 & 36.4 & 10.6 \\
\hline Rather unattractive & 0.0 & 23.2 & 27.3 & 36.4 & 21.6 \\
\hline Medium & 8.2 & 27.5 & 48.5 & 22.7 & 30.0 \\
\hline Rather attractive & 60.7 & 34.8 & 15.2 & 4.5 & 28.6 \\
\hline Very attractive & 29.5 & 10.1 & 0.0 & 0.0 & 9.2 \\
\hline
\end{tabular}




\subsection{Determinants of Farms' Nature-Values}

Higher SISAF index values (indicating higher nature-value) were associated with a greater proportion of male farmers. In Green farms, no farms were run by females, in contrast to Black farms where they comprised $9 \%$. The proportion of female farmers increased with the transition to lower classes. This would suggest that females were more critical in their assessment of their farms or that male farmers rate their farms more highly (Table 4). However, these results should be treated with caution due to the low percentage of farms run by women in the sample. The proportion of farms larger than 100 ha was higher in the Green (45.9\%) and Yellow farms (46.4\%) and around $40 \%$ in the Grey and Black farms. This suggests that the owners of larger farms place a higher nature-value on their farms than do the owners of smaller farms. This is contrary to the prevailing opinion, in which small farms are usually considered more environmentally friendly.

Table 4. Determinants used in the subjective assessment of nature-value.

\begin{tabular}{|c|c|c|c|c|c|}
\hline \multirow{2}{*}{ Specification } & \multicolumn{4}{|c|}{ Farm's Nature-Value-Typological Classes } & \multirow{2}{*}{ Total } \\
\hline & Green Farms & Yellow Farms & Grey Farms & Black Farm & \\
\hline \multicolumn{6}{|c|}{ Gender of farmer $(\%)$ : } \\
\hline Female & 0.0 & 2.9 & 4.0 & 9.1 & 3.7 \\
\hline Male & 100.0 & 97.1 & 96.0 & 90.9 & 96.3 \\
\hline \multicolumn{6}{|c|}{ Farm area (Percentage of farms in each class $(\%)$ : } \\
\hline up to 30 ha & 18.0 & 17.4 & 20.2 & 18.2 & 18.7 \\
\hline 30-100 ha & 36.1 & 36.2 & 40.4 & 40.9 & 38.5 \\
\hline above 100 ha & 45.9 & 46.4 & 39.4 & 40.9 & 42.9 \\
\hline \multicolumn{6}{|c|}{ Farm characteristics: } \\
\hline Age of farmers (years) & 45.4 & 45.7 & 43.6 & 44.4 & 44.6 \\
\hline Period of farming (years) & 21.8 & 23.7 & 20.0 & 22.2 & 21.7 \\
\hline Total farm area (ha) & 560.2 & 344.9 & 310.8 & 218.3 & 360.3 \\
\hline Area of arable land (median) & 537.8 & 312.4 & 291.1 & 199.4 & 335.6 \\
\hline \multicolumn{6}{|c|}{ Percentage $(\%)$ of farms with (Percentage of farms in each class $(\%)$ : } \\
\hline Individual trees & 80.3 & 82.6 & 77.8 & 75.0 & 79.1 \\
\hline Field margins & 78.7 & 66.7 & 65.7 & 50.0 & 66.3 \\
\hline Ponds & 63.9 & 56.5 & 45.5 & 43.2 & 52.0 \\
\hline Ditches up to $2 \mathrm{~m}$ wide & 82.0 & 75.4 & 71.7 & 56.8 & 72.5 \\
\hline Watercourse & 57.4 & 40.6 & 37.4 & 18.2 & 39.6 \\
\hline Line of trees & 54.1 & 49.3 & 48.5 & 29.5 & 46.9 \\
\hline Groups of trees & 67.2 & 69.6 & 53.5 & 45.5 & 59.3 \\
\hline Hedges and Shelter belts & 24.6 & 29.0 & 20.2 & 13.6 & 22.3 \\
\hline
\end{tabular}

In the survey, the age of farmers was similar in all categories. The average age was 45 years and the average length of time that a farmer had farmed his/her land was 22 years. The Green and Yellow farms had more natural landscape features, such as individual trees, field margins, ponds, ditches, lines of trees, and hedges. Black farms were perceived to have the least landscape elements; only $18 \%$ had watercourses, and $14 \%$ had hedges and shelter belts.

\subsection{Powers of Determinants}

Based on the designated generalized ordered logit regression model, the odds ratios for the independent quantitative variables and the individual levels of independent qualitative variables were compared to the selected (reference) level to determine the chances of a farm moving from a lower to a higher nature-value assessment class (Table 5). 
Table 5. Identification of determinants used in the subjective assessment of the nature-value of farms. Odds ratios from a generalised ordered logit regression model are reported.

\begin{tabular}{|c|c|c|c|}
\hline \multicolumn{4}{|c|}{ Determinants of Farm's Attractiveness } \\
\hline Factor & Reference Level & Odds Ratio & $p$-Value \\
\hline \multicolumn{4}{|c|}{ Socio-economic determinants of farms } \\
\hline Sex & male & 0.38 & 0.12 \\
\hline \multirow{2}{*}{\multicolumn{2}{|c|}{$\begin{array}{c}\text { Age } \\
\text { Farm area }\end{array}$}} & 1.00 & 0.90 \\
\hline & & 1.00 & 0.73 \\
\hline Farm development & Not increased & 1.05 & 0.84 \\
\hline \multicolumn{4}{|c|}{ Occurrence of landscape elements } \\
\hline Individual trees & no & 0.71 & 0.25 \\
\hline Field margins & no & 1.73 & $0.04 *$ \\
\hline Ponds & no & 1.25 & 0.39 \\
\hline Ditches up to $2 \mathrm{~m}$ wide & no & 1.38 & 0.24 \\
\hline Watercourse & no & 2.14 & $0.00^{* * *}$ \\
\hline Line of trees & no & 1.25 & 0.37 \\
\hline Groups of trees & no & 1.09 & 0.75 \\
\hline Hedges and shelter belts & no & 1.02 & 0.95 \\
\hline
\end{tabular}

Based on the obtained odds ratios (Table 5), it was found that factors such as the age of the farmer, size of the farm, or its development (determined by the fact of increasing the farm area over the last 10 years) did not increase the farm's chances of moving to a higher rating of natural attractiveness. Odds ratios below the value of 1 were obtained for farms run by women, in which chances to move to a class with higher attractiveness rating were lower than men but results were not significant (p-value 0.12).

On the other hand, comparing farms in which the analyzed landscape elements were present to those that did not have these elements, it was found that only farms with field margins and water courses were more likely to move to higher classes of nature attractiveness. In relation to farms that did not have these landscape elements, the chances were higher by $73 \%$ and $114 \%$, respectively. Other odds ratios were not statistically significant.

In addition to the subjective assessment of the natural attractiveness of their own farm, farmers were also asked about opinions on the importance for nature of the individual elements of the landscape and of practices used on their farm.

In Green farms, $73 \%-85 \%$ of farmers felt that agricultural practices had an impact on the nature-value of their farms. Over $85 \%$ of farmers (mostly Green farms) perceived the sowing of catch crops as an activity had a medium to strong impact on nature, and $74 \%$ indicated that fallow land had the least impact. In Black farms, fewer farmers believed that these agricultural practices affected nature. Between $57 \%$ and $68 \%$ of farmers expressed the opinion that agricultural practices impacted nature. Here, we only present the two extreme classes of nature-value: Green farms and Black farms (Figure 2).

Farmers who ran Green farms, more often than those who ran Black farms, expressed an opinion on the impact of the analyzed landscape elements and applied cultivation practices on nature. These differences were statistically significant except for the frequency of opinions on the impact of ditches and leguminous plants on nature (Figure 2). 


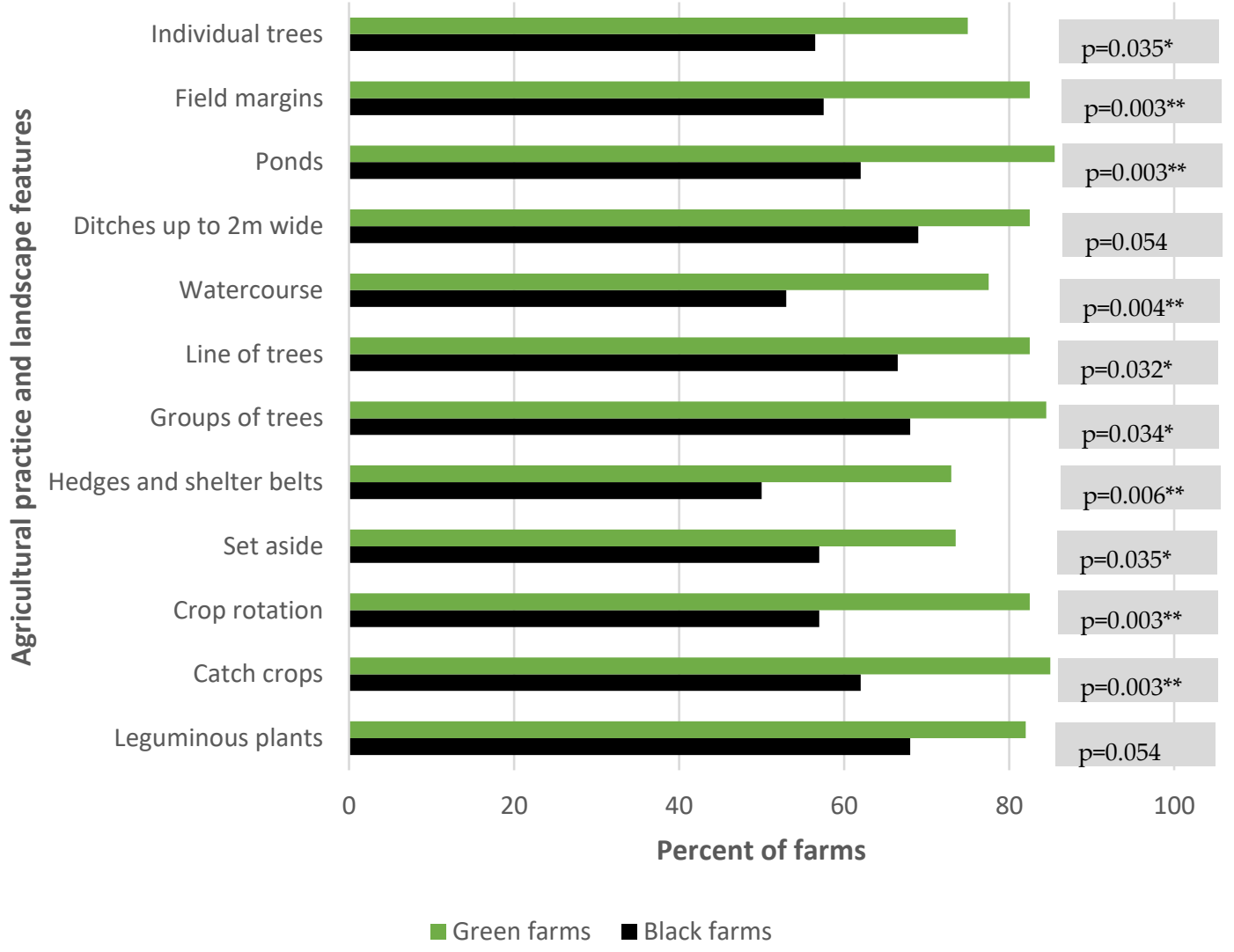

Figure 2. Percentage of farmers expressing opinion on the impact (average or strong) of individual agricultural practices and landscape features on the natural value of their farm. The symbol * denotes statistically significant differences: ${ }^{*}$ for $p<0.05$; ${ }^{* *}$ for $p<0.01$.

\section{Discussion}

The TOPSIS multidimensional linear ordering method [31,32] used in the study allowed a synthetic assessment of the subjective natural attractiveness of farms simultaneously in all six of its dimensions. The synthetic index allowed the creation of four classes of subjective assessment of farm attractiveness-from the highest rated green farms to the lowest rated Black farms. The one-dimensional analyses of diagnostic variables carried out in separate farm classes allowed for a typology of classes, and the average levels of features describing the farmers, farm, and environment were a means to identify the determinants of the farm's natural attractiveness.

Through analysis of the values of individual diagnostic variables it was also found that biodiversity is not perceived equally in all dimensions. Based on the results obtained, it was noticed that in the class with the highest rating of natural attractiveness there were no farms unattractive for pollinators, game, and birds, but there were just a few ( $2 \%-5 \%)$ unattractive for rodents, amphibians and reptiles, and non-crop plants. According to the authors in [35,36], the perception of biodiversity in these dimensions may be affected by all kinds of cultural conditions and stereotypes existing in society; e.g., combining biodiversity in these dimensions with neglect in running a farm. These studies would require some strengthening, and in the future could contribute to the identification and elimination of barriers hindering the promotion of biodiversity and increasing the attractiveness of farms. Another interesting observation made was the comparison of farmers' opinions on the impact of landscape elements on nature with the frequency of their occurrence on the farms. The vast majority of farmers believed that the studied landscape elements affected nature to a medium or strong degree. On Green farms, positive opinions on individual elements ranged between $73 \%$ and $85 \%$, and on Black farms between $50 \%$ and $70 \%$. It seems to be an important issue to identify factors that influence the introduction of individual landscape elements to farms and take action to increase biodiversity within them. Despite a good 
assessment, farmers value individual landscape features on their farms to varying degrees. This may be the result of economic and bureaucratic obstacles. According to experts, they can have a negative impact on the decisions taken by farmers despite their good attitude [37].

Only slightly more than one fifth of the farms were classified as Green farms with the highest nature assessment value. In this group, however, farmers rated the highest attractiveness in relation to wild game, and the lowest in relation to wild plants and pollinators. Wild boar (Sus scrofa) is considered both as a problem species and the most important game animal. This species, which causes the most damage to field crops, has grown in numbers throughout Europe since 1980. It may benefit from mild winters, deforestation, intensification of field crops, feeding, and a decreasing number of hunters. More conflicts have arisen on this connection [38]. This may affect the farmers' assessment. This is a problem area needing action. Being attractive to game animals does not automatically result in crop damage. Farms that value their attractiveness to game at the same time assess the natural attractiveness to non-crop plants, rodents, amphibians, and reptiles as low. It should be noted that the amphibian population is the most decreasing vertebrate group, population-wise. This is caused by the losses of habitats, pollution, and disease. Habitat fragmentation and loss is indicated as the most important factor in Europe [39].

Our study shows that the most nature attractive farms are those over 100 ha. However, the median area of farms in the survey was 336 ha and was larger than the average in Poland. This is due to the inclusion in the study of a few very large farms with areas over 1000 ha (the largest farm had an area of 13,000 ha), which affected the average. Attractiveness of large farms is in contrast to the theory that small farms are more environmentally friendly, have larger landscape heterogeneity, or a greater number of native plants [40]. This may be due to the fact that these large farms can afford a larger number of environmentally friendly elements. Their presence on the farm does not reduce the percentage of land intended for production. In contrast, small farms are forced to obtain more from a unit of land to achieve a satisfactory income. This fact is also known to agronomists [41]. In Brazil, large farms are forced by law to exclude from production, part of their area, and restore its original functions. This means that they can become more environmental friendly [42]. Finally, the size of farms is one of the factors, along with the intensity of production, the size of investments, and the number of cultivated plants affecting the decline of biodiversity [43]

Understanding the factors that motivate farmers to make conservation decisions is crucial to improving the relationship between farming and the environment. We need to be aware that farmers perceive the environment through the prism of the business that they manage. Compulsory adoption of regulations may bring about the opposite effect to that intended. Economic profit is important for producers, but they also make decisions based on their own world view and psychological prejudices, and non-economic motivations may also be more important than economic ones. Producers' motivations are important [44] and farmers understand the value of nature and how it must be protected at all stages of production.

Poland is among the countries with the highest level of biodiversity in Europe, although landscape is dominated by agricultural areas amounting to almost $60 \%$ of the land surface [45]. The high level of biodiversity is the result of Poland's position on the border of continental and Atlantic climates; the lack of natural barriers to the west and east of the country; and historical and economic conditions that have hindered the development of rural areas in the past. Nevertheless, the character of the Polish agricultural landscape has been changing very rapidly in recent years. The average size of farms is increasing, intensive cultivation practices are now common, and rural residents are becoming less directly connected to agriculture. Available scientific data investigating biodiversity are mainly focused on areas of Western Europe, which differ from Poland and other Central European countries. As a result, not every pro-environmental solution that works in other countries is rational in Polish conditions.

The problem of biodiversity conservation should be considered at many levels, starting from the lowest territorial units, taking into account local and landscape factors, and ending with whole regions. 
Maintaining a high level of biodiversity will translate into maintaining or even increasing the potential of ecosystem services [46].

Results show that encouraging farmers into pro-environmental activities only through financial incentives is not sufficient. Producers have to become more environmentally-friendly. If nothing changes, a situation will continue whereby environmental conservation groups will argue that the activities associated with greening are not beneficial to the environment, and conversely, farmers will highlight the perceived senselessness of the regulations. Reform of CAP should consider all parties and opinions. Farmers have a key role in meeting the demands for increased on-farm biodiversity levels, and the effectiveness of conservation measures depends on farmers [47] to make agricultural systems more sustainable [48]. Numerous studies have indicated that changes should be made, and robust scientific data is necessary to underpin these changes.

An alternative to the current payment model may be future payments for the results obtained. Such a model becomes an important point in the discussion on the future of the CAP. It can become more effective compared to the currently existing solution based on cost equalization. The current solution is based on a set of rules that tell you what to do, at what time, what not to do. Results based payments gives greater flexibility to the funding department, thus better adaptation to existing conditions [49]. New payment models could pay money to farmers; for example, if the protected area contains a certain number of indicator species. In this approach, farmers are positively oriented towards it, which is also what the public should be aware of. On the other hand, administrative personnel appear to be critical of this solution [50].

Other authors suggest that attention should be paid to the original EFA goals; namely, the support of biodiversity in agricultural areas. Taking into account and changing the relative weight of each EFA element should take place [51]. Lack of knowledge in regard to the positive impacts of greening on the environment may result in farmers' choosing the lowest cost option [13]. Financial incentives, if they are able to produce positive results in nature conservation, should be treated as an interim solution and not as the final protection measure, since they do not bring long-term stability. Programs should be directed towards voluntary activities, and those that are effective should increase farmers' involvement without the financial incentives [52]. Paying farmers to participate in environmental protection programs does not necessarily translate into protection activities, although on the other hand, a large proportion of farmers eagerly undertake pro-ecological activities without payment. Indeed, without external restrictions, farmers are more willing to take such action [53].

\section{Conclusions}

To the best of our knowledge, this is the first time that farmer's perceptions of their own farms in relation to the natural environment have been studied. Here, we used the TOPSIS method and the results provide valuable information in regard to farmland biodiversity $[54,55]$. Socio-economic factors, such as gender, also influenced the farm assessments. Men rated their farm better than women. This may indicate that they have overestimated their farms or that they are underestimated by women. The presence of field margins or watercourses by the farmers significantly increased the possibility that the farm would be classified as attractive for nature.

Author Contributions: Conceptualization: S.Ś. and Z.S.; data acquisition: S.Ś. and Z.S.; data analysis: S.Ś. and R.G-W.; design of methodology: S.Ś. and R.G.-W.; software development: S.Ś. and R.G.-W.; writing and editing: S.S., Z.S., and R.G.-W.

Funding: This research received no external funding.

Acknowledgments: The paper was financed within the framework of Ministry of Science and Higher Education programme 'Regional Initiative of Excellence' in years 2019-2022, Project No. 005/RID/2018/19. We thank Piotr Tryjanowski for insightful comments and for his help in improving the manuscript.

Conflicts of Interest: The authors declare no conflict of interest. 


\section{References}

1. Maxwell, S.L.; Fuller, R.A.; Brooks, T.M.; Watson, J.E. Biodiversity: The ravages of guns, nets and bulldozers. Nat. News 2016, 536, 143-145. [CrossRef] [PubMed]

2. ÓhUallacháin, D.; Copland, A.S.; Buckley, K.; McMahon, B.J. Opportunities within the Revised EU Common Agricultural Policy to Address the Decline of Farmland Birds: An Irish Perspective. Diversity 2015, 7, 307-317. [CrossRef]

3. Sherren, K.; Yoon, H.J.; Clayton, H.; Schirmer, J. Do Australian graziers have an offset mindset about their farm trees? Biodivers. Conserv. 2012, 21,363-383. [CrossRef]

4. $\quad$ Emmerson, M.; Morales, M.B.; Oñate, J.J.; Batáry, P.; Berendse, F.; Liira, J.; Aavik, T.; Guerrero, I.; Bommarco, R.; Eggers, S.; et al. How agricultural intensification affects biodiversity and ecosystem services. Adv. Ecol. Res. 2016, 55, 43-97.

5. Lomba, A.; Guerra, C.; Alonso, J.; Honrado, J.P.; Jongman, R.; McCracken, D. Mapping and monitoring high value farmland: Challenges in european landscapes. J. Environ. Manag. 2014, 143, 140-150. [CrossRef]

6. Davidson, M. Equity and the Conservation of Global Ecosystem Services. Sustainability 2017, 9, 339. [CrossRef]

7. Heldbjerg, H.; Sunde, P.; Fox, A.D. Continuous population declines for specialist farmland birds 1987-2014 in Denmark indicates no halt in biodiversity loss in agricultural habitats. Bird Conserv. Int. 2018, 28, 278-292. [CrossRef]

8. Uchida, K.; Koyanagi, T.F.; Matsumura, T.; Koyama, A. Patterns of plant diversity loss and species turnover resulting from land abandonment and intensification in semi-natural grasslands. J. Environ. Manag. 2018, 218, 622-629. [CrossRef]

9. Sustainable Land Use (greening). Available online: https://ec.europa.eu/agriculture/direct-support/greening en (accessed on 30 July 2019).

10. Cortignani, R.; Gobattoni, F.; Pelorosso, R.; Ripa, M. Green Payment and Perceived Rural Landscape Quality: A Cost-Benefit Analysis in Central Italy. Sustainability 2018, 10, 2910. [CrossRef]

11. Erjavec, K.; Erjavec, E. 'Greening the CAP'—Just a fashionable justification? A discourse analysis of the 2014-2020 CAP reform documents. Food Policy 2015, 51, 53-62. [CrossRef]

12. Solazzo, R.; Donati, M.; Arfini, F. Cap towards 2020 and the cost of political choices: The case of Emilia-Romagna region. Land Use Policy 2015, 48, 575-587. [CrossRef]

13. Świtek, S.; Sawinska, Z. Farmer rationality and the adoption of greening practices in Poland. Sci. Agric. 2017, 74, 275-284. [CrossRef]

14. Pe'er, G.; Zinngrebe, Y.; Hauck, J.; Schindler, S.; Dittrich, A.; Zingg, S.; Tscharntke, T.; Oppermann, R.; Sutcliffe, L.M.E.; Sirami, C.; et al. Adding some green to the greening: Improving the EU's Ecological Focus Areas for biodiversity and farmers. Conserv. Lett. 2017, 10, 517-530. [CrossRef]

15. Sereke, F.; Dobricki, M.; Wilkes, J.; Kaeser, A.; Graves, A.R.; Szerencsits, E.; Herzog, F. Swiss farmers don't adopt agroforestry because they fear for their reputation. Agrofor. Syst. 2016, 90, 385-394. [CrossRef]

16. Kross, S.M.; Ingram, K.P.; Long, R.F.; Niles, M.T. Farmer perceptions and behaviors related to wildlife and on-farm conservation actions. Conserv. Lett. 2018, 11, 1-9. [CrossRef]

17. Kaiser-Bunbury, C.N.; Mougal, J.; Whittington, A.E.; Valentin, T.; Gabriel, R.; Olesen, J.M.; Blüthgen, N. Ecosystem restoration strengthens pollination network resilience and function. Nature 2017, 542, 223. [CrossRef] [PubMed]

18. Rader, R.; Bartomeus, I.; Garibaldi, L.A.; Garratt, M.P.; Howlett, B.G.; Winfree, R.; Cunningham, S.A.; Mayfield, M.M.; Arthur, A.D.; Anderson, G.K.; et al. Non-bee insects are important contributors to global crop pollination. Proc. Natl. Acad. Sci. USA 2016, 113, 146-151. [CrossRef]

19. Patrício-Roberto, G.; Campos, M. Aspects of landscape and pollinators-What is important to bee conservation? Diversity 2014, 6, 158-175. [CrossRef]

20. Deinet, S.; Ieronymidou, C.; McRae, L.; Burfield, I.J.; Foppen, R.P.; Collen, B.; Böhm, M. Wildlife Comeback in Europe-The Recovery of Selected Mammal and Bird Species; Final report to Rewilding Europe by ZSL, BirdLife Internatonal and the European Bird Census Council; ZSL: London, UK, 2013.

21. Sanderson, F.J.; Kloch, A.; Sachanowicz, K.; Donald, P.F. Predicting the effects of agricultural change on farmland bird populations in Poland. Agric. Ecosyst. Environ. 2009, 129, 37-42. [CrossRef] 
22. Manton, M.; Angelstam, P.; Naumov, V. Effects of Land Use Intensification on Avian Predator Assemblages: A Comparison of Landscapes with Different Histories in Northern Europe. Diversity 2019, 11, 70. [CrossRef]

23. Hansen, N.A.; Scheele, B.C.; Driscoll, D.A.; Lindenmayer, D.B. Amphibians in agricultural landscapes: The habitat value of crop areas, linear plantings and remnant woodland patches. Anim. Conserv. 2018, 22, 72-82. [CrossRef]

24. Pulsford, S.A.; Lindenmayer, D.B.; Driscoll, D.A. Reptiles and frogs conform to multiple conceptual landscape models in an agricultural landscape. Divers. Distrib. 2017, 23, 1408-1422. [CrossRef]

25. Tschumi, M.; Ekroos, J.; Hjort, C.; Smith, H.G.; Birkhofer, K. Rodents, not birds, dominate predation-related ecosystem services and disservices in vertebrate communities of agricultural landscapes. Oecologia 2018, 188, 863-873. [CrossRef] [PubMed]

26. Fischer, C.; Gayer, C.; Kurucz, K.; Riesch, F.; Tscharntke, T.; Batary, P. Ecosystem services and disservices provided by small rodents in arable fields: Effects of local and landscape management. J. Appl. Ecol. 2018, 55, 548-558. [CrossRef]

27. Petit, S.; Gaba, S.; Grison, A.L.; Meiss, H.; Simmoneau, B.; Munier-Jolain, N.; Bretagnolle, V. Landscape scale management affects weed richness but not weed abundance in winter wheat fields. Agric. Ecosyst. Environ. 2016, 223, 41-47. [CrossRef]

28. Hwang, C.L.; Yoon, K. Multiple Attribute Decision Making Methods and Applications; Springer: Berlin, Germany, 1981.

29. Wołoszyn, A.; Głowicka-Wołoszyn, R.; Kozera, A. Application of Generalized Distance Measure to the construction of a synthetic index of subjective sense of financial security of farmers'households. Metody Ilościowe w Badaniach Ekonomicznych 2017, 18, 501-509. [CrossRef]

30. Sun, L.Y.; Miao, C.L.; Yang, L. Ecological-economic efficiency evaluation of green technology innovation in strategic emerging industries based on entropy weighted TOPSIS method. Ecol. Indic. 2017, 73, 554-558. [CrossRef]

31. Walesiak, M. Multivariate Statistical Analysis in Marketing Research; Wroclaw University of Economics: Wroclaw, Poland, 1993; Research Papers no. 654.

32. Jajuga, K.; Walesiak, M.; Bak, A. On the General Distance Measure. In Exploratory Data Analysis in Empirical Research. Studies in Classification, Data Analysis, and Knowledge Organization; Schwaiger, M., Opitz, O., Eds.; Springer: Berlin/Heidelberg, Germany, 2003.

33. Williams, R. Generalized Ordered Logit/Partial Proportional Odds Models for Ordinal Dependent Variables. Stata J. 2006, 6, 58-82. [CrossRef]

34. Brant, R. Assessing proportionality in the proportional odds model for ordinal logistic regression. Biometrics 1990, 46, 1171-1178. [CrossRef]

35. Siebert, R.; Toogood, M.; Knierim, A. Factors affecting European farmers' participation in biodiversity policies. Sociol. Rural. 2006, 46, 318-340. [CrossRef]

36. Herzon, I.; Mikk, M. Farmers' perceptions of biodiversity and their willingness to enhance it throug agri-environment schemes: A comparative study from Estonia and Finland. J. Nat. Conserv. 2007, 15, 10-25. [CrossRef]

37. Zinngrebe, Y.; Pe'er, G.; Schueler, S.; Schmitt, J.; Schmidt, J.; Lakner, S. The EU's ecological Focus area-How experts explain farmers' choices in Germany. Land Use Policy 2017, 65, 93-108. [CrossRef]

38. Massei, G.; Kindberg, J.; Licoppe, A.; Gačić, D.; Šprem, N.; Kamler, J.; Baubet, E.; Hohmann, U.; Monaco, A.; Ozoliňš, J.; et al. Wild boar populations up, numbers of hunters down? A review of trends and implications for Europe. Pest Manag. Sci. 2015, 71, 492-500. [CrossRef] [PubMed]

39. Bonk, M.; Pabijan, M. Changes in a regional batrachofauna in south-central Poland over a 25 year period. North-West. J. Zool. 2010, 6, 225-244.

40. Belfrage, K.; Björklund, J.; Salomonsson, L. Effects of farm size and on-farm landscape heterogeneity on biodiversity-Case study of twelve farms in a Swedish landscape. Agroecol. Sustain. Food Syst. 2015, 39, 170-188. [CrossRef]

41. Rosset, P. The Multiple Functions and Benefits of Small Farm Agriculture. In Proceedings of the Policy Brief 4, FAO/Netherlands Conference on the Multifunctional Character of Agriculture and Land, Maastricht, The Netherlands, 12-17 September 1999. 
42. Latawiec, A.E.; Crouzeilles, R.; Brancalion, P.H.; Rodrigues, R.R.; Sansevero, J.B.; Santos, J.S.; Mills, M.; Nave, A.G.; Strassburg, B.B. Natural regeneration and biodiversity: A global meta-analysis and implications for spatial planning. Biotropica 2016, 48, 844-855. [CrossRef]

43. Strohbach, M.W.; Kohler, M.L.; Dauber, J.; Klimek, S. High nature-value farming: From indication to conservation. Ecol. Indic. 2015, 57, 557-563. [CrossRef]

44. Semmelink, A.; Chan, K.; Satterfield, T. Farmers' relationship with nature: How and why it matters. In Proceedings of the Salish Sea Ecosystem Conference, Seattle, WA, USA, 4-6 April 2018.

45. Convention on Biological Diversity. Fifth National Report on the Implementation of the Convention on Biological Diversity. Poland, 2014.

46. Świtek, S.; Jankowiak, Ł.; Rosin, Z.M.; Sawinska, Z.; Steppa, R.; Takacs, V.; Zbyryt, A.; Tryjanowski, P. Jak zachować wysoki poziom bioróżnorodności na obszarach rolniczych w Polsce? Identyfikacja najważniejszych problemów badawczych. Wieś i Rolnictwo 2017, 4, 115-138.

47. Gabel, V.M.; Home, R.; Stolze, M.; Birrer, S.; Steinemann, B.; Köpke, U. The influence of on-farm advice on beliefs and motivations for Swiss lowland farmers to implement ecological compensation areas on their farms. J. Agric. Educ. Ext. 2018, 24, 233-248. [CrossRef]

48. Löprich, C. Agriculture in Europe: Greener practices and a brighter future for the sector. EPC Policy Brief, 30 May 2018.

49. Hasund, K.P.; Johansson, M. Paying for environmental results is WTO compliant. EuroChoices 2016, 15, 33-38. [CrossRef]

50. Birge, T.; Toivonen, M.; Kaljonen, M.; Herzon, I. Probing the grounds: Developing a payment-by-results agri-environment scheme in Finland. Land Use policy 2017, 61, 302-315. [CrossRef]

51. Van Vooren, L.; Reubens, B.; Broekx, S.; Pardon, P.; Reheul, D.; van Winsen, F.; Verheyen, K.; Wauters, E.; Lauwers, L. Greening and producing: An economic assessment framework for integrating trees in cropping systems. Agric. Syst. 2016, 148, 44-57. [CrossRef]

52. Mills, J.; Gaskell, P.; Ingram, J.; Dwyer, J.; Reed, M.; Short, C. Engaging farmers in environmental management through a better understanding of behaviour. Agric. Hum. Values 2017, 34, 283-299. [CrossRef]

53. Runhaar, H.; Polman, N.; Dijkshoorn-Dekker, M. Self-initiated nature conservation by farmers: An analysis of Dutch farming. Int. J. Agric. Sustain. 2018, 16, 486-497. [CrossRef]

54. Sutcliffe, L.M.; Batáry, P.; Kormann, U.; Báldi, A.; Dicks, L.V.; Herzon, I.; Kleijn, D.; Tryjanowski, P.; Apostolova, I.; Arlettaz, R.; et al. Harnessing the biodiversity value of Central and Eastern European farmland. Divers. Distrib. 2015, 21, 722-730. [CrossRef]

55. Tryjanowski, P.; Hartel, T.; Báldi, A.; Szymański, P.; Tobolka, M.; Herzon, I.; Goławski, A.; Konvicka, M.; Hromada, M.; Jerzak, L.; et al. Conservation of farmland birds faces different challenges in Western and Central-Eastern Europe. Acta Ornithol. 2011, 46, 1-12. [CrossRef] 